\title{
DAVID HUME A TRAVÉS DEL ESPEJO DE BORGES
}

\author{
DAVID HUME IN BORGES' LOOKING GLASS
}

\author{
Antonio José CANo López \\ UNED - CARTAGENA *
}

\begin{abstract}
Resumen: Jorge Luis Borges se sintió fascinado, desde los mismos inicios de su carrera literaria, por el idealismo. Fue la influencia del amigo de la familia Macedonio Fernández, así como las lecturas de Schopenhauer y Berkeley, las que propiciaron esta adhesión. Sin embargo, será la impronta del pensamiento de David Hume la que de forma decisiva definirá la coherencia teórica de las tesis borgianas, y la que establecerá un punto de unión entre la postura de Berkeley y la de Schopenhauer. Además, le permitirá llevar a cabo diferentes reflexiones en torno al problema del tiempo. David Hume está presente en lo que se ha considerado por la crítica como principales piezas literarias de Borges.
\end{abstract}

Palabras clave: Idealismo, Escepticismo, Mundo externo, Yo, Tiempo, Eterno retorno.

\footnotetext{
* Profesor Tutor de la UNED. Centro Asociado de Cartagena, Calle Ingeniero de la Cierva, 28, Cartagena 30203. E-mail: ajcano@cartagena.uned.es. Catedrático de Filosofía en el IES "Jiménez de la Espada» (Cartagena). Doctor en Filosofía con la Tesis Doctoral: La teoría de las pasiones en David Hume (Del modelo clásico de las pasiones al paradigma ilustrado), Universidad de Murcia, 2009. Su publicación más reciente: «Hume y la concepción de las pasiones en Four Dissertations» en: Araucaria. Revista Iberoamericana de Filosofía, Politica, Humanidades y Relaciones Internacionales, año 20, no 40. Segundo semestre de 2018. Pp. 285-310.
} 
АвsтRACT: Jorge Luis Borges was fascinated by idealism since the beginning of his literary career. It was the influence of his family friend Macedonio Fernández, as well as reading philosophers like Schopenhauer and Berkeley, that propitiated his adhesrence to idealism. However, it was the influence of David Hume's thinking which decisively defined the theoretical coherence of the Borges' theses, and which established a point of attachment between the position of Berkeley and that of Schopenhauer. Moreover, it allowed him to carry out different reflections on the problem of time. David Hume is present in what critics consider to be Borges' main literary pieces.

KeYwords: Idealism, Skepticism, External world, Self, Time, Eternal recurrence.

\section{Introducción}

Desde bien temprano surgió en Borges la propensión y fascinación por el credo idealista por influencia del amigo de la familia Macedonio Fernández y las lecturas realizadas de Berkeley y Schopenhauer. Ya en Inquisiciones, su primer volumen en prosa, publicado en Buenos Aires en 1925, dedica dos importantes ensayos al asunto. Se trata de «La nadería de la personalidad» $\mathrm{y}$ «La encrucijada de Berkeley». Esta impronta idealista ya era clara en el poemario que abre su iniciación literaria, Fervor de Buenos Aires, publicado dos años atrás.

Sin embargo, será la lectura de David Hume la que establecerá el puente entre un tipo de idealismo y otro. Hume lleva a sus máximas consecuencias el pensamiento de Berkeley, a la vez que establece un sólido nexo con la concepción schopenhauriana del mundo como representación y voluntad. La presencia del escocés es tal en la obra de Borges, que aparece en los principales ensayos, poesías y cuentos. En El libro de la arena (1975) escribe: «Le dije que a Escocia yo la quería personalmente por el amor de Stevenson y de Hume» (Borges, 2005b: 70). Es más, su referencia intermitente, pero constante, nos permite establecer hilos de unión entre los géneros, dando coherencia a algunos de los asuntos recurrentes y obsesivos de Borges. Muchos son los temas que Borges recoge en sus textos, y que comparte con Hume: la irrealidad del mundo externo, el laberinto de la identidad personal, la concepción idealista de lo real amparada en la asociación de ideas, el problema de la relación causal de los hechos, el escepticismo irónico, 
la revelación de la creación del mundo por un torpe demiurgo, la consideración de la concepción naturalista de lo existente, etc. Vano es el intento de abarcarlo todo, más aún porque Borges diversifica y bifurca los temas, remitiéndolos a un sistema múltiple de autores, citas y textos. Así, por ejemplo, con respecto al problema de la «identidad personal», tan pronto lo refiere a Heráclito, a las disputas medievales, como a Hume, a Schopenhauer o el budismo. Y en otras ocasiones, sin mencionar a autores, escuchamos resonar ecos de filosofías por las que transita. Por ello, nos centraremos en los textos en los que la presencia de Hume es explícita y contundente, para llevar a cabo una reflexión que tiene por objeto iluminar algunos aspectos de la obra de Borges, así como, y principalmente, recorrer alguno de los caminos posibles del pensar humeano.

En relación con el cuento, el relato que Borges calificase como más ambicioso de su carrera literaria, ampliamente comentado por la crítica, «Tlön, Uqbar, Orbis Tertius», se sustenta y fascina en base a una argumentación filosófica que tiene su origen en la concepción filosófica de Berkeley y Hume. La descripción del universo de Tlön coincide con las tesis empiristas sobre el «mundo externo» y el «yo», en las que sus naciones son "congénitamente» idealistas. El cuento se fundamenta en las especulaciones sobre el idealismo que Borges inició en los ensayos referidos de Inquisiciones y que ha desarrollado en el que ha sido considerado por la crítica como su más importante ensayo: La «Nueva refutación del tiempo» (1944-1946), que representa el marco teórico desde el que interpretar el mundo de Tlön.

De esta época cabe citar también otra referencia a Hume en el poema «La noche cíclica», escrito en Uruguay en 1940, junto a una primera versión del cuento de «Tlön, Uqbar, Orbis Tertius» (Balderston, 2017). Sin embargo, la referencia resulta extraña, Borges escribe:

Volverá toda noche de insomnio: minuciosa.

La mano que esto escribe renacerá del mismo

vientre. Férreos ejércitos construirán el abismo.

(David Hume de Edimburgo dijo la misma cosa.)

(2005a: 863) 
En «La noche cíclica», Borges no menciona a Hume como un filósofo idealista, sino que de forma extrańa lo relaciona con la «doctrina de los ciclos». Algo que puede dejar perplejos a los principales intérpretes de la obra humeana. En Historia de la Eternidad, en la edición de 1943, Borges incluirá el ensayo «El tiempo circular», donde de nuevo se hará referencia a Hume y se aclara esa inclusión.

¿Qué tienen en común estos textos? Generar la perplejidad metafísica a partir de la cuestión que Borges considera como esencial de la misma: la temporalidad, porque «el problema del tiempo nos toca más que los otros problemas metafísicos. Porque los otros son abstractos. El del tiempo es nuestro problema. ¿Quién soy yo? ¿Quién es cada uno de nosotros? ¿Quiénes somos?» (Borges, 2017: 501). Así, negar el tiempo, afirmarlo, no es sino vivenciarlo, pensarlo en sus límites. Si en otros textos Borges se sirve de Heráclito, Platón, Plotino, San Agustín o Schopenhauer para reflexionar sobre el tiempo, con Hume se vale de la perspectiva idealista y de su capacidad paródica de imaginar otras formas de lo real, poniendo entre paréntesis la materialidad y la corporeidad, para colocarnos frente a nuestra existencia desnuda, porque lo que está en juego, al fin y al cabo, es nuestro «sentido de la existencia».

El Hume del que Borges hace uso en su obra es tal vez, el que más posibilidades literarias tiene, aquel cuyas doctrinas causan mayor asombro, pero también, el que más íntimamente está unido a esa angustia borgiana del hombre perdido en un universo caótico y desasosegado por el fluir temporal. En «El idioma analítico de John Wilkins», Borges recoge una cita de Hume que pone el orden de lo real en entredicho: «El mundo -escribe David Hume- es tal vez el bosquejo rudimentario de algún dios infantil, que lo abandonó a medio hacer, avergonzado de su ejecución deficiente; es obra de un dios subalterno, de quien los dioses superiores se burlan; es la confusa producción de una divinidad decrépita y jubilada, que ya se ha muerto (Dialogues Concerning Natural Religion, V. 1779)» (Borges, 2005a: 708). La filosofía y el lenguaje son intentos vanos de ordenar el universo, pero el ser humano sigue intentando salir de ese laberinto inmanente que supone entender el yo, el mundo y la historia. Partiendo de esas premisas podremos adentrarnos en la imagen de «Hume a través del espejo de Borges», como la Alicia de Lewis Carroll, perdida en un mundo invertido que nos desvela el sentido de lo real. El propio Borges ya advierte que las imágenes mentales son comparables a las especulares, caso de que existiese el mundo real, y con ello los espejos (Borges, 2017: 258). El símbolo del "espejo» no es para Borges la imagen que nos devuelve la nitidez buscada, al contrario, es 
deformador, amenazante, evasivo e invasivo, incluso se cierne en los límites del territorio de la sinrazón ${ }^{1}$. Borges rinde tributo y admiración a la figura de David Hume, pero mirarse en su espejo desafía la conformidad con la crítica, y entre la variedad múltiple de lo real hay un Hume diverso a sus intérpretes, que no comprenden que buscar la fidelidad al mensaje auténtico de Hume es empresa vana, y ellos mismos, en la medida que se confrontan en una batalla hermenéutica, corroboran lo inagotable de la interpretación.

En el presente trabajo intentaremos acercarnos a la imagen que nos ofrece Borges de Hume, a través de los textos referidos. En primer lugar, deberemos entender la relación existente entre la literatura de Borges y la filosofía, sus afinidades secretas, para así, en un segundo momento, comprender cómo Borges se vale del pensamiento humeano como fuente de inspiración de sus textos fundamentales, a la vez que nos permite mostrar otros sentidos de la filosofía del escocés.

\section{Borges y la filosofía}

¿Qué relación mantuvo Borges con la filosofía? ¿Puede considerarse a Borges como un filósofo? Mucho se ha escrito sobre el tema. Para algunos intérpretes, como, por ejemplo, Juan Nuño, «que en Borges haya ciertos y determinados temas filosóficos no deberá nunca entenderse como que su propósito fue hacer filosofía y menos aún que su obra entera rezuma o contiene claves metafísicas que sólo esperan por su despertar» (Nuño, 1986: 13). La obra de Borges lo muestra como un espíritu obsesionado con ciertos temas metafísicos, que plasma en sus ensayos, en sus poemas y en sus cuentos, pero sin llevar a cabo una labor de discusión o argumentación filosófica. Para el crítico literario Anderson Imbert, Borges es un nihilista con un vasto conocimiento de todas las escuelas filosóficas, las cuales utiliza para la elaboración de sus cuentos, pero sin participar vitalmente en ninguna de ellas. Precisamente cuando María Esther Vázquez le refiere a Borges esta observación, Borges confirma: «No soy filósofo ni metafísico; lo que he hecho es explotar o explorar -es una palabra más noble- las posibilidades

1 Véase la Antología del escritor y crítico literario Andres Ibánez con título $A$ través del espejo (2016) que recoge los mejores relatos sobre espejos, de autores como Borges, Hoffmann, Poe, Rilke, Juan Valera, Ángela Carter, entre otros. 
literarias de la filosofía» (Vázquez, 1984: 118). El «idealismo», o cualquier otra tendencia metafísica, presente en alguna de sus obras es, más un uso literario, que una convicción. El propio Borges señala: «Si fuera idealista, esto sería una certidumbre y yo no tengo certidumbres: más bien tengo dudas... Si he participado de esta filosofía, ha sido para propósitos particulares del cuento y mientras lo escribía» (1984: 119)².

Carla Cordua es de la misma opinión que Juan Nuño, el recurso a la metafísica está en función del asombro y la maravilla que producen, y no sólo esto, sino también la ironía, la parodia, y toda clase de juegos literarios, así, según Cordua: «Del desmantelamiento irónico de los prodigios metafísicos procederán algunos de los materiales de las narraciones de Borges; de la parodia de ciertos argumentos filosóficos, la descripción de las situaciones centrales de una serie de cuentos» (Cordua, 1997: 116). Las referencias filosóficas únicamente son artificios literarios, que están puestos al servicio de una estética. Borges declaraba en el «Epílogo» de Otras Inquisiciones: «Dos tendencias he descubierto, al corregir las pruebas, en los misceláneos trabajos de este volumen. Una, a estimar las ideas religiosas o filosóficas por su valor estético y aun por lo que encierran de singular y de maravilloso. Esto es, quizá, indicio de un escepticismo esencial» (Borges, 2005a: 775). Para Borges la metafísica es una rama de la literatura fantástica. El recurso a temas filosóficos está subordinado, por tanto, a valores de tipo estético, y nunca a proposiciones o discursos de verdad. Esto explicaría las distorsiones en torno al pensamiento de diferentes filósofos y lo que algunos han considerado como referencias de poco rigor académico. Incluso podría ser acusado de intrusismo en un territorio ajeno. En las primeras líneas de la «Nota Preliminar» del ensayo «Nueva refutación del tiempo», perteneciente a Otras Inquisiciones Borges señala que este ensayo es un «débil artificio de un argentino extraviado en la metafísica» (2005a: 757), lo cual podría significar que no es un experto en esta insigne disciplina.

2 Una carta a su amigo Jacobo Sureda de junio de 1921, parece contradecir las declaraciones de Borges, manifestando una auténtica dedicación por la metafísica: «Yo, de ti me arrojaría de cabeza en el estudio de la metafísica. Encuentro que el Libre Albedrío, el Determinismo, el problema de si existe o no el Yo, el estudio de lo que son Tiempo y Espacio, el problema del conocimiento, etc.... son mucho más interesantes que lo de oírle a un poeta relatar que la luna parecía una claraboya o que su novia tiene trenzas rubias. ¿Y qué es la literatura, en general, sino un barajar de asociaciones o nimiedades como ésas?» (Borges, Cartas del fervor. Correspondencia con Maurice Abramowicz y Jacobo Sureda (1919-1928), pp. 201-202). 
Sin embargo, y pese a estos testimonios, debemos aclarar ciertos aspectos respecto a la relación de su obra con la filosofía y la metafísica. En primer lugar, debemos mantener que Borges ha escrito al menos una serie de ensayos que es posible calificarlos de "filosóficos», así, por ejemplo, «Historia de la Eternidad», "La doctrina de los ciclos», «El tiempo circular» o "Nueva refutación del tiempo». Este último ensayo le ha servido a Ulises Moulines para demostrar que Borges es un «auténtico filósofo», pues en él, Borges manifiesta una seriedad filosófica al analizar el problema del tiempo partiendo del idealismo y las teorías relativistas (Moulines, 1999). El hecho de que estas piezas estén dentro de una amplia miscelánea ensayística puede parecer que se pierdan como obras filosóficas, cuando claramente están introduciendo un análisis y argumentación racional. Es más, en los ensayos de Historia de la Eternidad, Borges refiere la "Bibliografía» utilizada, como si se tratase de trabajos académicos.

Borges también proyectó un libro sobre los presocráticos y otro sobre Spinoza, ambos en colaboración, pero que finalmente no prosperaron. Confesaba en una entrevista a Marcos Ricardo Barnatán realizada en 1974, que estaba trabajando con una señora de Azevedo en un libro sobre Baruj Spinoza, del que todavía no habían escrito una sola línea, pero en el que trabajaban intensamente, leyendo todo lo que se había publicado. Pero su valoración es importante al señalar que la mayoría de lo que leen es poco interesante, pues «no se puede interpretar a un autor con los mismos términos que ese autor emplea. Casi todos los textos utilizan ese mismo lenguaje geométrico que Spinoza inventó. Salvo el capítulo que le dedica Russell en su Historia de la Filosofía» (Barnatán, 1978: 105). Borges rechaza todo academicismo, incluso declara la insuficiencia hermenéutica de aquellos que interpretan a un filósofo siguiendo la terminología propia y específica del autor. Esta línea a lo Russell, ciertamente dificulta que Borges pueda ser admitido en la comunidad filosófica.

Por otro lado, si bien es cierto que el cuento no es de por sí un género filosófico, la brevedad y las elipsis narrativas sobre las que se asienta suponen un reto intelectual para el lector, a diferencia de la novela que nos transporta a lo largo de sus páginas. Además, las narraciones de Borges sugieren y cuestionan ideas filosóficas, son, como bien dice Vinzenzo Vitiello, auténticos contes philosophiques (Vitiello, 2007: 51). En este sentido, recordemos la admiración que Borges profesaba por Voltaire, cuyos cuentos, tales como "Cándido o el optimismo», ironizaban sobre los aspectos teológicos de la metafísica de Leibniz. 
Borges es, como afirma Carlos Ulises Moulines, «filósofo», porque «nos induce a hacernos preguntas inquietantes sobre cuestiones tales como el infinito, la eternidad, el tiempo, la identidad personal, la posibilidad del solipsismo, en una palabra, cuestiones centrales de la filosofía de todos los tiempos» (Moulines, 1999: 179). Los temas referidos para numerosos ensayos, poesías y cuentos entran de lleno en el corazón directo de la filosofía. La obra de Ana María Barrenechea, La expresión de la irrealidad en la obra de Jorge Luis Borges, nos muestra un espléndido catálogo que bien pudiera servir como introducción a la filosofía de Borges.

Los textos de Borges pretenden hacernos reflexionar sobre asuntos filosóficos, en unos textos donde los verdaderos protagonistas no son los personajes, sino las ideas. Ahora bien, Borges no escribe con un empeño filosófico preconcebido que después traslada a la literatura, como podría contemplarse en las obras teatrales o en las novelas de Jean-Paul Sartre, sino que su estilo literario en el que abundan las paradojas, la ironía, el oxímoron, etc., fluye del propio acontecer poético, borrándose la frontera entre literatura y filosofía. Es tal vez este aspecto el que más ha despistado a la crítica. Más bien, como dice Beatriz Sarlo, Borges suele concebir sus relatos como la "puesta en forma de hipótesis filosóficas»:

Borges imagina la puesta en escena de una pregunta no planteada abiertamente en la trama, sino presentada como ficción en el desarrollo de un argumento que es, al mismo tiempo, teórico y narrativo. Esto no implica que cada uno de sus cuentos traiga la solución de un problema; por el contrario, Borges trabaja básicamente con la paradoja, los escándalos lógicos y los dilemas, presentados en situación filosófico-narrativa. Las ideas no se apoderan de la voz de los personajes, ni se presentan fuera del despliegue de la trama, sino que constituyen su verdadera sustancia y la configuran desde dentro (Sarlo, 2007: 95).

Podemos ahora matizar la "posición filosófica» de Borges, para entender el uso que hace de la filosofía, en nuestro caso del pensamiento de Hume. Es importante observar, como él mismo declara, que estimar las ideas filosóficas por su valor estético es indicio de un «escepticismo esencial», un escepticismo que implica la deconstrucción de los metarrelatos de la metafísica. Pero ese giro 
epistemológico hacia un paradigma estético es propio de lo que posteriormente se denominaría "postmodernidad». Estas consideraciones han hecho que, como dice Jesús Rodero, «muchos críticos sitúen a Borges como precursor de la postmodernidad, como impulsor de los juegos de simulación postmodernos: relativización radical, muerte de la certeza más allá del discurso, instauración de la pluralidad significativa, en definitiva, la postulación de la literatura como discurso de simulación lúdica» (Rodero, 2006: 74). Alfonso de Toro ha insistido en que Borges es uno de los grandes pensadores del siglo XX y un precursor de la postmodernidad (De Toro, 1999).

El escepticismo es una concepción o actitud filosófica con la que Borges se siente identificado (Castany Prado, 2012). El hecho de que el escepticismo se eleve por encima de las diferentes doctrinas filosóficas, guardando cierta distancia ante ellas, para apreciarlas como intentos de comprensión de la realidad, pero sin comprometerse con ninguna, puede haber forjado el malentendido de que Borges era ajeno a la filosofía. Este escepticismo se vertebra en su obra confrontando opiniones o sistemas opuestos. Según Borges, en el mismo nacimiento de la filosofía está ya presente el carácter dialógico del pensamiento. En el «Prólogo» al libro de entrevistas con Osvaldo Ferrari, En diálogo, Borges afirma:

Unos quinientos años antes de la era cristiana se dio en la Magna Grecia la mejor cosa que registra la historia universal: el descubrimiento del diálogo. La fe, la certidumbre, los dogmas, los anatemas, las plegarias, las prohibiciones, las órdenes, los tabúes, las tiranías, las guerras y las glorias abrumaban el orbe; algunos griegos contrajeron, nunca sabremos cómo, la singular costumbre de conversar. Dudaron, persuadieron, disintieron, cambiaron de opinión, aplazaron. Acaso los ayudó su mitología, que era como el shinto, un conjunto de fábulas imprecisas y de cosmogonías variables. Esas dispersas conjeturas fueron la primera raíz de lo que llamamos hoy, no sin pompa, la metafísica. Sin esos pocos griegos conversadores la cultura occidental es inconcebible (Borges \& Ferrari, 2005: 7).

Si la esencia de la filosofía reside en la conversación, en el diálogo, entonces el valor de la filosofía no está tanto en la configuración de una concepción del mundo, formulada en un sistema coherente y cerrado de enunciados, en forma 
de monólogo y expresado como credo de certezas, sino en un escepticismo compartido, dialéctico, surgido de la duda y la incertidumbre. Borges gustará de oponer sistemas como perplejidades confrontadas, que nos devuelven a la esencia del pensar. En el relato de «Tlön, Uqbar y Orbis Tertius», los habitantes idealistas del planeta imaginado de Tlön si bien afirman que «la metafísica es una rama de la literatura fantástica», a ello añaden la consideración de que «saben que un sistema no es otra cosa que la subordinación de todos los aspectos del universo a uno cualquiera de ellos», y que, por lo tanto, podrán darse diversas explicaciones de la realidad en base al elemento que prioricemos. El carácter dialógico de la filosofía, como confrontación de doctrinas, es recogido en las mismas líneas del relato: «El hecho de que toda filosofía sea de antemano un juego dialéctico, una Philosophie des Als Ob, ha contribuido a multiplicarlas» (2005a: 436).

Únicamente es posible partir de la postura escéptica, de la puesta entre paréntesis de las certezas y los sistemas filosóficos, del juego de las oposiciones, y de hacerles recorrer el camino del absurdo, llevando sus tesis a sus consecuencias últimas. A Borges le gusta repetir que «Hume notó para siempre que los argumentos de Berkeley no admiten la menor réplica y no causan la menor convicción» (2005a: 435 y 217). Hume al respecto señaló que esta es la señal del escepticismo, no es posible rebatir los argumentos escépticos, pero es imposible seguirlos en la vida cotidiana, «su único efecto», -afirma Hume-, «es causar este momentáneo aturdimiento, irresolución y confusión que es el resultado del escepticismo» (Hume, 2004: 333). En «Nueva refutación del tiempo», así como en «Tlön, Uqbar y Orbius Tertius», tras haber demostrado la imposibilidad del tiempo, o la perfección del universo idealista que se impone al mundo real, Borges da un giro en el que parece volver al vivir cotidiano, negando los postulados racionales de los que había partido. El escepticismo le lleva a desmontar cualquier interpretación de un orden universal. Queda el reino de la posibilidad, valga decir de la ficción y la fantasía. Es leyendo a Borges en clave escéptica como pueden superarse las reticencias de la crítica a la hora de hablar de filosofía en Borges. Un escepticismo, que, por cierto, comparte con David Hume. 


\section{El idealismo en Borges y Hume}

\subsection{Interpretando a Hume en clave idealista}

La estrategia más clara y directa que ha utilizado Borges para llegar a la incertidumbre sobre lo real ha sido la del camino del «idealismo». A la hora de interpretar a Hume, Borges lo asimila a la corriente idealista. Sin embargo, esta interpretación no es aceptada por muchos intérpretes de Hume, el mismo Borges reconoce en «Nueva refutación del tiempo» que tanto Berkeley, como Hume «abundan en párrafos que contradicen o excluyen mi tesis» (2005a: 757), esto es, que su razonamiento es una interpretación, que no tiene porqué ser la más adecuada a sus filosofías, aunque según él, es la más coherente, y, según Borges "creo haber deducido, no obstante, la consecuencia inevitable de su doctrina" (2005a: 757).

La contraposición clásica entre Empirismo y Racionalismo, entre la fundamentación del conocimiento en la experiencia versus la razón deductiva, parece contradecir la inclusión de Hume dentro de la metafísica idealista, en primer lugar, porque Hume inaugura las filosofías de corte antimetafísico, dudando de la capacidad de la razón de alcanzar los fundamentos últimos de la realidad, y en segundo lugar, porque el psicologismo de Hume está unido, cuando no subordinado, a elementos epistemológicos, que intentan determinar el ámbito legítimo del saber. Sólo una visión sesgada del Libro I del Tratado de la naturaleza humana puede darnos una visión de Hume como filósofo idealista. Sin embargo, hasta prácticamente la publicación de la obra de Norman Kemp Smith, The Philosophy of David Hume, en 1941, la filosofía de Hume era reconocida como la propia de un escepticismo extremo que surgía a partir de las tesis del psicologismo del Treatise. Hume estaría en la línea de lo que algunos intérpretes denominan la «vía de las ideas» (Benitez \& Robles, 1994: 111). Una línea interpretativa que tendría sus orígenes en el idealismo cartesiano. Descartes habría iniciado una revolución en el pensamiento al hacer depender la verdad no de criterios objetivos, sino del sujeto, del yo y sus ideas. Para Descartes, no conocemos las cosas directamente, sino las ideas. John Locke habría descubierto en Descartes los fundamentos de una nueva filosofía, en abierta oposición al aristotelismo dominante en las Universidades. Locke recogió así el legado cartesiano de lo que se ha dado en llamar la «vía de las ideas», que continuarían Berkeley y Hume, legítimos herederos de 
las doctrinas de Descartes. Si bien, la concepción lockeana negaría la existencia de ideas innatas (Cano López, 2009: 83-88).

Borges no parece haber hecho este recorrido por la historia del idealismo moderno, y sólo da protagonismo a Descartes de forma tardía en su poema homónimo, publicado en su poemario La cifra, en 1981, donde parece recuperar a Descartes relacionándolo con los temas del «yo como ilusión» y la «existencia como sueño»:

\section{«Descartes»}

Soy el único hombre en la tierra y acaso no haya tierra ni hombre

Acaso un dios me engaña.

Acaso un dios me ha condenado al tiempo, esa larga ilusión.

Sueño la luna y sueño mis ojos que perciben la luna.

He sońado la tarde y la mañana del primer día.

He soñado a Cartago y a las legiones que desolaron Cartago.

He soñado a Lucano.

He soñado la colina del Gólgota y las cruces de Roma.

He soñado la geometría.

He sońado el punto, la línea, el plano y el volumen.

He sońado el amarillo, el azul y el rojo.

He soñado mi enfermiza niñez.

He sońado los mapas y los reinos y aquel duelo al alba.

He sońado el inconcebible dolor.

He sońado mi espada.

He soñado a Elisabeth de Bohemia.

He soñado la duda y la certidumbre.

He soñado el día de ayer.

Quizá no tuve ayer, quizá no he nacido.

Acaso sueño haber soñado.

Siento un poco de frío, un poco de miedo. 
Sobre el Danubio está la noche.

Seguiré sońando a Descartes y a la fe de sus padres.

(2005b: 295)

Para Hume, Descartes es un autor que intentando escapar del escepticismo de Sexto Empírico, de Montaigne, de Gassendi y buscando unos fundamentos sólidos del saber que superasen los inciertos principios de la Escolástica, cayó en un abismo aún mayor. Pues fue más radical que Pirrón, dudando de la realidad exterior en el ámbito fenoménico (algo que no ponían en duda los seguidores de Pirrón), así como de la certeza matemática e incluso de la propia razón. Con Descartes, el escepticismo alcanzó un nivel mayor que con cualquier otro pensador de la época, de ahí haya sido calificado el suyo como el «escepticismo más profundo». Para Hume, si el sistema cartesiano fuese cierto no habría necesidad de ir más allá del cogito. Para él, la duda como método para acceder a un principio del que derivar todo conocimiento es un absurdo epistemológico, pues supone poner en cuestión nuestras facultades, nuestra propia capacidad de razonar, no pudiendo alcanzar ningún conocimiento cierto. Persistir en la duda, carecer de creencias, es algo que, según Hume, no puede ser mantenido por criatura alguna. En la Investigación sobre el entendimiento humano, Hume aceptará una forma "moderada» de aquel escepticismo, que como tal es una excelente iniciación a la filosofía, pues dudar de nuestros prejuicios y opiniones adquiridos por la educación, nos pone en el camino de la correcta investigación. En esta obra, Hume incluye a Berkeley en la tradición escéptica, cuando curiosamente, como el mismo Hume indica, aquél escribe sus Diálogos entre Hylas y Philonus "contra escépticos y ateos", pero sus argumentos contra la existencia de la realidad material son auténticamente escépticos, por cuanto «no admiten contestación ni producen convicción. Su único efecto es producir el asombro momentáneo, la irresolución y confusión, que son el resultado del escepticismo» (Hume, 2004: 331).

El escepticismo moderno se fundamenta en el idealismo. Borges considerará a Berkeley como «inventor» de la doctrina idealista (Borges, 2005a: 760). Y si bien señala más adelante que «el idealismo es tan antiguo como la inquietud metafísica», vislumbrando esta forma de pensamiento en aquellos que negaron la realidad de este mundo, como los platónicos, los teólogos, o los defensores del Idealismo Absoluto, Berkeley es considerado como «su apologista más agudo» (2005a: 766). 
Para explicar la posición idealista, Borges cita extensamente a Berkeley:

Berkeley (Principles of Human Knowledge, 3) observó: «Todos admitirán que ni nuestros pensamientos ni nuestras pasiones ni las ideas formadas por nuestra imaginación existen sin la mente. No menos claro es para mí que las diversas sensaciones, o ideas impresas en los sentidos, de cualquier modo, que se combinen (id est, cualquiera sea el objeto que formen), no pueden existir más que en una mente que las perciba... Afirmo que esta mesa existe; es decir, la veo y la toco. Si al estar fuera de mi escritorio, afirmo lo mismo, sólo quiero decir que, si estuviera aquí la percibiría, o que la percibe algún otro espíritu. Hablar de la existencia absoluta de cosas inanimadas, sin relación al hecho de si las perciben o no, es para mí insensato. Su esse es percipi; no es posible que existan fuera de las mentes que las perciben». En el párrafo 23 agregó, previniendo objeciones: «Pero, se dirá, nada es más fácil que imaginar árboles en un prado o libros en una biblioteca, y nadie cerca de ellos que los percibe. En efecto, nada es más fácil. Pero, os pregunto, ¿que habéis hecho sino formar en la mente algunas ideas que llamáis libros o árboles y omitir al mismo tiempo la idea de alguien que los percibe? Vosotros, mientras tanto, ¿no los pensabais? No niego que la mente sea capaz de imaginar ideas; niego que los objetos puedan existir fuera de la mente». En otro párrafo, el número 6, ya había declarado: «Hay verdades tan claras que para verlas nos basta abrir los ojos. Una de ellas es la importante verdad: Todo el coro del cielo y los aditamentos de la tierra -todos los cuerpos que componen la poderosa fábrica del universo- no existen fuera de una mente; no tienen otro ser que ser percibidos; no existen cuando no los pensamos, o sólo existen en la mente de un Espíritu Eterno» (2005a: 759-760).

Berkeley negó la realidad exterior, la materia, para él, lo real sólo existe para la mente que lo percibe. Toda otra forma de concebir la realidad es una duplicación innecesaria ${ }^{3}$. Pero para explicar la continuidad de los objetos, tuvo que recurrir

3 Es por ello que los espejos tienen algo de monstruoso. Al comienzo del relato de «Tlön, Uqbar, Orbis Tertius», Bioy Casares recuerda de una Enciclopedia apócrifa que «uno de los heresiarcas de Uqbar había declarado que los espejos y la cópula son abominables, porque multiplican el número de los hombres» (Borges, 2005a: 431). 
a la Divinidad, lo que le resultaba gratificador para la defensa de su sistema teológico. Hume, sin embargo, lo corrigió, no era preciso acudir a tal instancia trascendente, el obispo Berkeley, queriendo reafirmar la religión, había abierto la caja de Pandora de la metafísica. Ni siquiera, según Hume, era posible afirmar el «yo» como una sustancia en la que subsistían las ideas, como defendía Descartes y corroboraba Berkeley. Únicamente existe una corriente de percepciones que se suceden unas a otras, no hay un sujeto metafísico detrás de esos continuos cambios. Es a partir de aquí como Borges construye la imagen de Hume, refiriendo las tesis escépticas del Libro I del Tratado de la Naturaleza Humana, en el que se niega la «identidad personal», y en el que muchos intérpretes, desde Thomas Reid a Bertrand Russell, han reconocido el pensamiento de Hume.

\subsection{Las consecuencias extremas del idealismo: "Nueva refutación del tiempo»}

Pero Borges piensa que debemos tomarnos en serio el «laberinto» en el que Hume confesaba habernos introducido (Hume, 1981: 884), y tener el valor de recorrerlo. Mientras que Hume no volvió en su obra posterior sobre estos temas, Borges parece haber recogido el testigo, tan habituado a pasear por laberintos y a imaginar mundos posibles. Y para Borges, la consecuencia lógica y radical del atomismo psicológico del yo consiste en la «refutación del tiempo».

Al inicio del ensayo Borges seńala que esta refutación del tiempo bien hubiera merecido «una línea de Huxley o de Kemp Smith» (2005a: 757). Con ello Borges nos da una pista de sus lecturas. Dos obras principales de la hermenéutica humeana refiere Borges: la obra de Thomas Henry Huxley, sobre Hume, dentro de la colección «English Men of Letters Series» de 1878 y The Philosophy of David Hume de Norman Kemp Smith, publicada en 1941, que supuso un giro en los planteamientos de la interpretación de Hume. En la caracterización que Borges hace de Hume en «Nueva refutación del tiempo», en principio parece estar lejos del "agnosticismo epistemológico» de Huxley (que sólo considera válido el conocimiento probado mediante la demostración científica), así como del «naturalismo» de Kemp Smith. Pues Borges parte del Hume escéptico, tanto del mundo material, posición que ha recogido de Berkeley, como de la identidad 
personal. Pero esa realidad que parece desvanecerse ante sí, aun se sustenta según Borges en la idea de tiempo. Tanto Berkeley como Hume afirman el tiempo, para Berkeley como «sucesión de ideas que fluye uniformemente y de la que todos los seres participan» y en Hume «una sucesión de momentos indivisibles». El mundo idealista es posible describirlo de la siguiente manera:

Un mundo de impresiones evanescentes; un mundo sin materia ni espíritu, ni objetivo ni subjetivo; un mundo sin la arquitectura ideal del espacio; un mundo hecho de tiempo, del absoluto tiempo uniforme de los Principia; un laberinto infatigable, un caos, un sueño. A esa casi perfecta disgregación llegó David Hume (2005a: 761).

Si admitimos los argumentos idealistas, según Borges es posible ir más lejos, sacando todas sus consecuencias. Si negamos la materia y el espíritu, y también el espacio, que son continuidades, ¿por qué no negar el tiempo? «Fuera de cada percepción (actual o conjetural) no existe la materia; fuera de cada estado mental no existe el espíritu; tampoco el tiempo existirá fuera de cada instante presente» (2005a: 768). Si partimos del atomismo mental humeano en el que cada percepción es una existencia distinta no sólo caemos en el «laberinto» al que Hume nos condena en el «Apéndice» del Tratado de la Naturaleza Humana, disolviendo el yo, sino que, además, se vuelve inaccesible cualquier continuidad. El tiempo no es posible fuera de cualquier momento presente, pero este momento se agota en sí mismo, sin relación alguna con cualquier otro.

Borges corrobora la disolución de la temporalidad al relatar una experiencia íntima:

Paseando por la localidad de Barracas siente que esas luces, esas veredas, la higuera, las calles, la noche, forman parte de algo que ya ha vivido muchos años atrás, en su infancia. Es más, intuye la identidad de los dos momentos. No se trata de un remontarse en el tiempo, sino más bien sentirse fuera del tiempo, tal vez muerto, poseedor de la eternidad. Pero si hay dos momentos idénticos, la cadena de causas y efectos que conforman el ayer y el hoy se 
desintegraría, «el tiempo -dice Borges- si podemos intuir esa identidad, es una delusión: la indiferencia e inseparabilidad de un momento de su aparente ayer y otro de su aparente hoy, bastan para desintegrarlo» (2005a: 765). Si una vivencia se repite es porque resulta la misma, lo que permite «desbaratar y confundir la historia del mundo» (2005a: 769).

Podríamos suponer también que, si vivimos un mismo momento, si se repite una vivencia, la rueda que encadena todos los acontecimientos volverá a reproducirse en su mismidad. De ahí tal vez que Borges a continuación, y en otros textos, se vea seducido por la idea del Eterno retorno.

A partir de la dialéctica de Berkeley y Hume, Borges concluye en la concepción de Schopenhauer ${ }^{4}$, en la que, citando su obra El mundo como voluntad y representación, «la forma de aparición de la voluntad es sólo el presente», pues el pasado y el porvenir sólo existen por un encadenamiento de la conciencia en el momento actual. Schopenhauer llega a identificar el tiempo con «un círculo que girara infinitamente: el arco que desciende es el pasado, el que asciende es el porvenir; arriba, hay un punto indivisible que toca la tangente y es el ahora» (2005a: 770). Una concepción que surge y lo acerca a las doctrinas budistas, y que permite comprender el pensamiento de Hume ligado a alguna forma de la doctrina de los ciclos.

Sin embargo, tras esta reflexión a la que nos conduce la metafísica idealista, esa forma de pensar irrebatible, nuestra creencia natural sobre la «realidad» se impone, y en esto Borges coincide con la interpretación naturalista que Kemp Smith hace del pensamiento de Hume. Tal vez el ensayo sólo ha sido un intento de convencernos de que nuestra existencia es ilusoria, como un consuelo, al decir de Borges, frente al fluir temporal y a una existencia que no llegamos a comprender, ni tal vez, aceptar:

And yet, and yet... Negar la sucesión temporal, negar el yo, negar el universo astronómico, son desesperaciones aparentes y consuelos secretos.

4 Para el estudio de la relación entre Borges y Schopenhauer, véase el interesante artículo de Iván Almeida «De Borges a Schopenhauer» (2004).

ÉNDOXA: Series Filosóficas, n. ${ }^{\circ}$ 42, 2018, pp. 355 -387. UNED, Madrid 
Nuestro destino (a diferencia del infierno de Swedenborg y del infierno de la mitología tibetana) no es espantoso por irreal; es espantoso porque es irreversible y de hierro. El tiempo es la sustancia de que estoy hecho. El tiempo es un río que me arrebata, pero yo soy el río; es un tigre que me destroza, pero yo soy el tigre; es un fuego que me consume, pero yo soy el fuego. El mundo, desgraciadamente, es real; yo, desgraciadamente, soy Borges (2005a: 770-771).

La esencia de nuestro yo es la temporalidad, un continuo pasar, un perpetuo tránsito, un irreversible suceder. Imaginar otros posibles tal vez sea sólo un consuelo, aunque es preciso considerar que la literatura y el pensamiento acometen también una labor de resistencia (como Borges pudo comprender en la última etapa de su labor literaria).

\subsection{Pensar dentro de los límites del idealismo: Hume en el planeta de Tlön}

Tal como se va desentrańando, conforme avanza el cuento de «Tlön, Uqbar, Orbis Tertius», Tlön es un planeta inventado por los habitantes del país imaginario de Uqbar. Una sociedad secreta del siglo XVII ideó la invención de un país fantástico, Uqbar, bajo los auspicios de los estudios herméticos, la filantropía y la cábala. Dicha fraternidad, perseguida en Europa, se trasladó dos siglos después a América. En Menphis, un millonario decidió apoyar el proyecto, ampliándolo a la invención de un planeta, con la condición de que la empresa se mantuviese en secreto y no pactase con el impostor Jesucristo. La creación se plasmó en una Enciclopedia, que tomaba como modelo la Encyclopaedia Britannica, y en la que se concretaban entre otros aspectos, los lenguajes de las naciones de ese planeta, el sistema de numeración, su concepción de la realidad y las distintas herejías que la contradecían. A principios del siglo XX, esta secta hizo llegar a sus trescientos colaboradores el Tomo XI de la Enciclopedia de Tlön, y anunció la preparación de los 40 tomos de la Enciclopedia, no ya en inglés, sino en alguno de sus idiomas. El título de la Enciclopedia era Orbis Tertius, el «Tercer Mundo», pues la concepción de los habitantes de Tlön era «idealista», siguiendo los preceptos de 
Berkeley y Hume, lo que condicionaba su forma de entender la realidad, y sus diversas lenguas.

La trama del relato, de gran complejidad, se desvela al final de la narración, en un «Apéndice» fechado en 1947, curiosamente seis años después de la publicación del cuento original, lo que sitúa la narración en un marco profético. Ya en este momento, la perfección idealista de Tlön se ha impuesto a nuestra débil e imperfecta realidad. El sueño de unos hombres, plasmado en una Enciclopedia fantástica, ha conquistado nuestro mundo «real».

«Tlön, Uqbar y Orbis Tertius» viene a ser la plasmación de las especulaciones teóricas que Borges iniciase en los ensayos referidos más arriba. Cuando Borges presenta la doctrina idealista en «Nueva refutación del tiempo» señala que "comprenderla es fácil; lo difícil es pensar dentro de sus límites» (2005a: 415). En el relato, Borges intenta pensar dentro de esos límites un mundo en el que sus habitantes son congénitamente idealistas, y, por lo tanto, la realidad no la constituyen los «objetos» en el espacio, sino las «ideas» que se suceden en su mente. Así pues, sin referencia espacial, sino sólo temporal, una serie de actos mentales que, a la manera humeana, resultan independientes unos de otros. La ausencia en Tlön de «objetos reales» determina sus lenguas, así en Tlön no contemplan los sustantivos, de los que carecen, basando sus idiomas y dialectos en «verbos impersonales» (por ejemplo, a la palabra luna le corresponde el verbo lucecer o lunar), o en "acumulación de adjetivos» (luna se diría aéreo-claro sobre oscuro-redondo o anaranjado-tenue-del cielo). Y en su literatura abundan los "objetos ideales», a la manera de Meinong, "convocados y disueltos en un momento, según las necesidades poéticas» (2005a: 435). Sólo una ciencia es posible, la «psicología», cualquier otro saber queda subordinado a ella. Aquí es dónde se muestra un mundo a la medida de las concepciones de Berkeley y Hume:

He dicho que los hombres de ese planeta conciben el universo como una serie de procesos mentales, que no se desenvuelven en el espacio sino de modo sucesivo en el tiempo. Spinoza atribuye a su inagotable divinidad los atributos de la extensión y del pensamiento; nadie comprendería en Tlön la yuxtaposición del primero (que sólo es típico de ciertos estados) y del segundo -que es un sinónimo perfecto del cosmos-. Dicho sea con otras palabras: no conciben que lo espacial perdure en el tiempo. La percepción de una humareda en el horizonte y después del campo incendiado y después del 
cigarro a medio apagar que produjo la quemazón es considerada un ejemplo de asociación de ideas (2005a: 436).

Vemos que el «idealismo» conduce, como en "Nueva refutación del tiempo», a una reflexión sobre el «tiempo». Y de igual manera que en este ensayo, la consecuencia lógica de un mundo perceptual es la negación del tiempo, como así lo propone una de las escuelas de Tlön. Borges niega el «tiempo objetivo», como Aristóteles en su Física, pues del tiempo una parte ya ha sido y no es, mientras que otra parte todavía no es, y parece aceptar el «tiempo subjetivo o psicológico» de Agustín de Hipona en Las Confesiones cuando entiende el pasado como recuerdo y el futuro como expectativas, modalidades ambas del momento "presente». Pero desde la perspectiva humeana, el "presente» aparece como «indefinido", formado por un conjunto de momentos ideales que no mantienen relación entre sí, por lo que no se suceden, sino que se disuelven, como imágenes evanescentes.

En el cuento, Borges contrarresta la posición de aquellos que afirman la realidad del instante presente con otras hipótesis plausibles, como la de Russell en The Analysis of Mind, cuando supone la reciente creación de nuestro planeta con unos habitantes que recuerdan un "pasado ilusorio", o con las no menos coherentes con el idealismo como las siguientes:

Otra escuela declara que ha transcurrido ya todo el tiempo y que nuestra vida es apenas el recuerdo o reflejo crepuscular, y sin duda falseado y mutilado, de un proceso irrecuperable. Otra, que la historia del universo -y en ellas nuestras vidas y el más tenue detalle de nuestras vidas- es la escritura que produce un dios subalterno para entenderse con un demonio. Otra, que el universo es comparable a esas criptografías en las que no valen todos los símbolos y que sólo es verdad lo que sucede cada trescientas noches. Otra, que mientras dormimos aquí, estamos despiertos en otro lado y que así cada hombre es dos hombres (2005a: 437).

Todas estas hipótesis son formas de negar el tiempo. De ahí se sigue la imposibilidad de un sujeto idéntico, que perdure a través de sus vivencias, dado que 
ninguna sustancia ni objeto se extiende a través de un tiempo discontinuo. Al carecer los objetos y los actos de continuidad espacial y temporal se excluyen el "principio de identidad» y el «principio de causalidad» en nuestra interpretación de la realidad.

Borges recurriendo a la filosofía como un «juego dialéctico» del «como si», motivado por el asombro, a modo de contrapunto, pondrá en escena a un heresiarca de Tlón que propondrá la escandalosa hipótesis «materialista». La existencia de objetos materiales supone concebir una realidad aparte de nuestras ideas. La hipótesis, rechazada por desafiar el «sentido común» idealista, pondrá en cuestión los fundamentos del mundo de Tlön, no solventándose la cuestión hasta que otro heresiarca de tradición ortodoxa proponga una hipótesis que nosotros denominaríamos spinoziana, y que Borges considera cercana a Schopenhauer: la del "panteísmo idealista», según la cual "hay un solo sujeto, que ese sujeto indivisible es cada uno de los seres del universo y que éstos son los órganos y máscaras de la divinidad» (2005a; 438). Definitivamente es la postura aceptada en Tlön pues tiene a su favor varias razones, «la primera, el repudio del solipsismo; la segunda, la posibilidad de conservar la base psicológica de las ciencias; la tercera, la posibilidad de conservar el culto de los dioses» (2005a: 438). La postulación de un sujeto único y eterno incide en la literatura, donde es raro que los libros estén firmados (tema recurrente en otros textos clásicos de Borges), en las matemáticas, donde la «operación de contar modifica las cantidades», etc.

En la Postdata de 1947, el orden preciso del idealismo filosófico de las naciones de Tlön ha triunfado y se ha impuesto a nuestra vacilante realidad. El narrador del relato vaticina que pronto desaparecerán de nuestro planeta los idiomas, para dejar paso a las nuevas lenguas postuladas en la Enciclopedia Orbis Tertius. Afirma: «El mundo será Tlön». Si bien Tlön es un laberinto, al menos es un laberinto ideado por los hombres, dada nuestra incapacidad de entender el mundo que nos rodea. La creación de una Enciclopedia, ese «espejo conceptual del mundo» (Sarlo, 2007: 109) ha terminado por dar vida a un nuevo mundo. Como dice Beatriz Sarlo: «Los sabios de Tlön inventan filosofías del "como si", no sólo para interpretar el mundo sino también para modificar el modo en el que lo percibimos; luego esa percepción ("como si") se imprime sobre el mundo y lo adecúa según la forma en como este es pensado» (2007: 112).

Nuestra «realidad» ha sucumbido ante el orden racional de Tlön, ante su «rigor de ajedrecistas», «su historia armoniosa» (Borges, 2005a: 443). El narrador, mientras tanto, desde un hotel de Adrogué (un lugar de memoria, ligado a la 
niñez de Borges), sucumbe a la indiferencia, apegado a un pasado incierto (no en vano se dedica a traducir un texto de Browne), tal vez, como única forma de hacer frente a un final apocalíptico.

El cuento de Borges se ha interpretado como una crítica de Borges a la inconsistencia del pensamiento realista, ante la inconmensurabilidad de las leyes del lenguaje y el oculto e indescifrable orden de lo real. De ahí la apuesta a favor del idealismo. Pero tal interpretación es errónea o al menos incompleta, pues en el relato la concepción idealista se desboca, comenzando a multiplicarse los objetos a la manera de Meinong, copiándose sin fin e invadiendo la realidad. De ahí que algunos intérpretes hayan caracterizado el relato como una reductio ad absurdum del idealismo (Botero Camacho, 2006). La aparente economía del mundo de Tlön es ficticia, y el principio de no contradicción es insostenible en él. $\mathrm{Al}$ menos en el mundo «real» nos regimos por un límite según el cual «no todo lo pensable existe» (Almeida, 2006: 114).

Aunque tampoco queda claro que Borges pretendiese refutar el idealismo, pues si bien se ha mostrado su inconsistencia formal, su imperio o dominio no deja de ser una ficción. Resulta más plausible concebir el relato como la puesta en forma de una hipótesis filosófica, como explicamos al concebir la relación de Borges con la filosofía. De esta manera, Borges se ha servido del pensamiento de Hume para reflexionar sobre alguna de sus perplejidades: lo real, el tiempo, la identidad personal.

\section{Más allá del idealismo: La doctrina de los ciclos}

Para Borges, la «negación del tiempo» era la consecuencia extrema del idealismo humeano, una tesis que el propio Hume no se atrevió a formular. Pero en ese «juego dialéctico» en el que consiste la filosofía, Hume proporcionaría a Borges otra variación sobre el tiempo: la idea del eterno retorno de lo mismo.

En 1943, Borges añadía a una nueva edición de Historia de la Eternidad, el ensayo «El tiempo circular» en el que declaraba: «Yo suelo regresar eternamente al Eterno Regreso» (2005a: 393). Era este uno de los temas que siempre estuvo presente en sus obras y al que recurría a modo de obsesión. Precisamente en este 
ensayo señala que la idea del Eterno Retorno aparecía recogida en los Diálogos sobre la religión natural de David Hume. Y en una entrevista, muchos años después, Borges revelaría a María Esther Vázquez, que la primera persona que le habló de esa doctrina fue su padre y que éste la recogió de la citada obra de Hume (Borges, 1983).

Borges ya había hecho uso del argumento de Hume, sin mencionar al filósofo, en el ensayo "La doctrina de los ciclos», en la primera edición de Historia de la Eternidad (1936), si bien actualizándola al introducir una referencia a la doctrina atómica de Rutherford.

En el ensayo de 1943, «El tiempo circular», Borges teoriza sobre el Eterno Retorno, y los tres modos fundamentales en los que, según él, se ha manifestado. El primero, refiere al «argumento astrológico» del Timeo platónico, donde se manifiesta que todos los planetas volverán a ocupar la misma posición que en su origen y que todo se volverá a repetir; el segundo es el más divulgado, el señalado por Nietzsche y del que Borges descubre un antecedente en los Diálogos sobre la religión natural, cuando Hume afirma:

No imaginemos la materia infinita, como lo hizo Epicuro; imaginémosla finita. Un número finito de partículas no es susceptible de infinitas trasposiciones; en una duración eterna, todos los órdenes y colocaciones posibles ocurrirán un número infinito de veces. Este mundo, con todos sus detalles, hasta los más minúsculos, ha sido elaborado y aniquilado, y será elaborado y aniquilado: infinitamente (Dialogues, VIII) (Borges, 2005a: 394; Hume, 2004a: 136).

En los Diálogos sobre la religión natural, Hume había introducido esta hipótesis cosmológica como una explicación posible del cosmos, una explicación materialista, tan coherente o más que la hipótesis teológica del designio 5 . Hume entendía aquí la filosofía al modo de Borges, como un «juego dialéctico»,

5 Es precisamente en la parte VIII de los Diálogos sobre la religión natural, donde Hume aventura las argumentaciones más arriesgadas para explicar el misterio del universo, contra el argumento teológico del designio. Para David O’Connor al defender la «vieja hipótesis 
amparado en un escepticismo, que ponía en entredicho cualquier forma de explicación sobre aquello que trascendiese la experiencia. Hume recuperaba así la "doctrina del eterno retorno» de los antiguos griegos como contrapunto de la concepción cristiana del universo. Su argumento partía de la idea de una materia finita en un universo donde transcurre un tiempo infinito, y en el que, por tanto, se repetirán todos los acontecimientos, y además de un modo infinito, durante toda la eternidad. Hume introducía aquí otra de las ideas que venía obsesionando a Borges, la del «infinito». De hecho, Georg Bossong ha caracterizado a Borges como pensador de lo infinito, (Bossong, 1988, 33). Sus símbolos preferidos como son las imágenes de los espejos (los espejos enfrentados), el laberinto, el reloj de arena, el tiempo cíclico, la eternidad, la biblioteca (de Babel) suponen una prefiguración del mismo. A la presencia del infinito le confería Borges un aire de amenaza. En el ensayo "Avatares de la tortuga» declara: «Hay un concepto que es el corruptor y el desatinador de los otros. No hablo del Mal cuyo limitado imperio es la ética; hablo del infinito" (2005a: 254). La idea de infinito deja así una estela de desolación, como bien señala Ana María Barrenechea «Borges sabe que toda realidad se disuelve con la presencia del infinito y lo convoca constantemente en sus obras, a veces aludiéndolo en una palabra, otras desarrollándolo en complejo argumento» (Barrenechea, 1984: 19). La misma autora refiere una cita de la obra de Borges, de El idioma de los argentinos (1928):

Sospecho que la palabra infinito fue alguna vez una insípida equivalencia de inacabado; ahora es una de las perfecciones de Dios en la teología y un discutidero en la metafísica y un énfasis popularizado en las letras y una finísima concepción renovada en las matemáticas -Russell explica la adición y multiplicación y potenciación de números cardinales infinitos y el porqué de sus dinastías casi terribles- y una verdadera intuición al mirar el cielo (Barrenechea, 1984: 18).

Estas referencias a lo inacabado, a las perfecciones de Dios, o su inclusión en el universo matemático, dan una serie de pistas sobre el verdadero sentido del «infinito». Si analizamos las reflexiones de Borges sobre este concepto y las

epicúrea» modificada, Hume se está convirtiendo en un precursor de la teoría del Big Bang, como más adelante de la teoría de la evolución de Darwin (O’Connor, 2001: 137-145). 
relacionamos con otros aspectos de su obra podemos comprobar cómo Borges expresa poéticamente la condición del ser humano extraviado en un universo regido por una Divinidad, cuyos designios nos están vedados conocer, o por un orden secreto e impenetrable, tal como refería Hume también en los Diálogos sobre la religión natural, que hacen fracasar nuestra búsqueda insaciable de un «sentido».

Borges intentó refutar esta concepción del Eterno retorno mediante la tesis matemática sobre el Infinito de Cantor. Pues si es posible un número infinito de combinaciones de la materia, ya no resulta necesario un Regreso Infinito. Es a través de la postulación de un infinito material, a partir de una hipótesis matemática, como Borges niega la doctrina de los ciclos. Pese a lo atractivo de la idea del Eterno Retorno, y a pesar de utilizarla en relatos tales como «Las ruinas circulares» o en el poema "La noche cíclica», Borges descree de la hipótesis. Es más, la siente como una amenaza, como una pesadilla, al igual que el Infinito, muy lejos de aquella apreciación de Nietzsche que servía para afirmar la vida.

Resulta ahora sencillo de explicar la inclusión de David Hume en el poema de 1940, "La noche cíclica», así como el aire de pesadilla que recorre este poema sobre la "doctrina de los ciclos», como puede apreciarse al introducir los términos: «arduos, oprimirá, gemirá, fétido, insomnio, abismo, oscura, noche, esquina remota, higuera sombría, vereda rota, rosa apagada, etc». Reproducimos el poema:

La noche cíclica

A Sylvina Bullrich

Lo supieron los arduos alumnos de Pitágoras:

los astros y los hombres vuelven cíclicamente;

los átomos fatales repetirán la urgente

Afrodita de oro, los tebanos, las ágoras.

En edades futuras oprimirá el centauro

con el casco solípedo el pecho del lapita;

cuando Roma sea polvo, gemirá en la infinita

noche de su palacio fétido el minotauro. 
Volverá toda noche de insomnio: minuciosa.

La mano que esto escribe renacerá del mismo vientre. Férreos ejércitos construirán el abismo.

(David Hume de Edimburgo dijo la misma cosa).

No sé si volveremos en un ciclo segundo como vuelven las cifras de una fracción periódica; pero sé que una oscura rotación pitagórica noche a noche me deja en un lugar del mundo que es de los arrabales. Una esquina remota que puede ser del Norte, del Sur o del Oeste, pero que tiene siempre una tapia celeste, una higuera sombría y una vereda rota.

Ahí está Buenos Aires. El tiempo que a los hombres trae el amor o el oro, a mí apenas me deja esta rosa apagada, esta vana madeja de calles que repiten los pretéritos nombres de mi sangre: Laprida, Cabrera, Soler, Suárez... Nombres en que retumban (ya secretas) las dianas, las repúblicas, los caballos y las mañanas, las felices victorias, las muertes militares. Las plazas agravadas por la noche sin dueño son los patios profundos de un árido palacio y las calles unánimes que engendran el espacio son corredores de vago miedo y de sueño.

Vuelve la noche cóncava que descifró Anaxágoras; vuelve a mi carne humana la eternidad constante y el recuerdo ¿¿l proyecto? de un poema incesante: 
«Lo supieron los arduos alumnos de Pitágoras...»

(Borges, 2005a: 863-864).

Posteriormente, Borges intentó escribir un cuento cuyo argumento girase en torno a Hume y la idea del Eterno Retorno, que finalmente no llegó a realizar. Así, tras el éxito de Ficciones, Borges continuó con la labor de idear argumentos para sus contes philosophiques, y en Febrero de 1945, en la Revista Latitud en una «Encuesta para escritores» al preguntarle qué preparaba, declaró que una serie de cuentos sobre la ciudad de los inmortales, sobre Averroes, sobre contrabandistas y "otro cuento fantástico sobre el tema del eterno retorno, que se titulará, si no me equivoco, "El traductor de Hume"» (Borges, 2001: 353). Lo curioso es que los cuentos posteriores que va alumbrando no hacen referencia al tema y en 1949, cuando publica El Aleph, únicamente hay una referencia tangencial a Hume, en "La busca de Averroes», y no en relación con la doctrina del eterno retorno. Sin embargo, como ya hemos referido la idea nunca la abandonó.

Existe un tercer modo del Eterno Retorno para Borges, «el menos pavoroso y melodramático, pero también el único imaginable». Según esta concepción, los ciclos del tiempo «serían similares, pero no idénticos» (2005a: 394). Es la propuesta que aparece en la mitología de las edades de Hesíodo, en el fuego de Heráclito, en Bacon, en Vico, en Schopenhauer, en el Eureka de Poe... y también en la doctrina del Buda, como menciona y se encargará de desarrollar en su célebre conferencia sobre el budismo (Borges \& Jurado, 2000). Borges, como filósofo le critica la negación del pasado y del porvenir y, por lo tanto, de cualquier novedad. Y en la citada entrevista con María Esther Vázquez, vuelve a criticarla:

En las cosmogonías hindúes, en el budismo, por ejemplo, los ciclos se repiten, pero no son idénticos: es decir, una persona no vive su propia vida un número indefinido o infinito de veces, sino que cada ciclo influye en el subsiguiente y así podemos descender a animales, a plantas, a demonios, a fantasmas, o podemos volver a ser otra vez hombres y eventualmente podemos perder nuestra identidad. Eso sería el Nirvana y eso sería la mayor felicidad, caer en la rueda de la vida y vernos libres de la vida. Esa idea me impresionó muchísimo y luego la he aprovechado muchas veces. Personalmente, descreo de ella. No solamente descreo, sino, como dije en un artículo titulado «La doctrina de los ciclos», si ésta es la milésima vez que 
mantenemos esta conversación, es realmente la primera porque no recuerdo las anteriores. Un argumento que suele emplearse a favor de esa idea, sobre el cual tiene un poema muy lindo el poeta Dante Gabriel Rossetti ( I have been here before, / But when or how I cannot tell: / I know the grass beyond the door, I The sweet keen smell, / The sighing sounds, the lights around the shore. I... You have been mine befare...»), es que, si yo creo haber vivido ya este momento, eso introduce una modificación, porque suponiendo que ésta sea la segunda vez que mantengo esta conversación y pienso: "yo ya he hablado sobre esto con María Esther Vázquez y le he dicho las mismas cosas en esta misma sala de la misma Biblioteca Nacional», entonces esto no habría ocurrido la primera vez, entonces los ciclos no serían idénticos. El hecho de recordar un ciclo anterior sería en realidad un argumento contra la doctrina de los ciclos. Además, si suponemos una sucesión indefinida o infinita de vidas, cada vez recordaremos mejor las cosas y eso nos permitirá modificar quizá nuestra conducta, y entonces se derrumbaría la teoría (Borges, 1983).

$\mathrm{La}$ «doctrina de los ciclos» que surgió en el pensamiento de Hume, resultó ser una idea fructífera para la especulación sobre el tiempo y la eternidad, sobre lo finito y lo infinito, sobre nuestra condición humana, como también un excelente recurso literario para los ensayos, los poemas y los cuentos de Borges. Sin embargo, a partir de las reflexiones borgianas, se manifiesta como un sistema de pensamiento con incoherencias formales profundas, que no logra proporcionarnos una respuesta a los enigmas de la existencia. De ahí que debamos entender la filosofía de Borges más como «juego dialéctico», que como un «sistema», lo que nos mostrará lo necesario de peregrinar por sus laberintos. 


\section{Conclusiones}

La imagen de David Hume visto a través del espejo de Borges nos desvela la concepción de un pensador que lleva a cabo, como Borges, juegos con el tiempo $\mathrm{y}$ con el infinito, que siente la angustia del existir en un universo desordenado, e instala la paradoja en el corazón mismo de la filosofía.

Lejos de muchas interpretaciones académicas, Hume aparece en el espacio borgiano asociado a la representación de una realidad que niega sus mismos fundamentos, así, la materia y el espacio, la identidad y la causalidad, el sujeto y el tiempo. Una salida posible aparece en la "doctrina de los ciclos», que Hume formuló en los Diálogos sobre la religión natural, pero tan incoherente como cualquier otra hipótesis que postule un orden racional del universo. La representación borgiana de Hume dejará perplejos a muchos intérpretes de su obra. Una visión difícil de comprender si no se entiende la filosofía como diálogo incesante, escepticismo irónico, juego dialéctico, en definitiva, como dicha del pensamiento. Borges y sus obsesiones, ya lo indicó Foucault al inicio de Las palabras y las cosas, es una fuente de inspiración para el ejercicio del pensamiento, también para explorar nuevas miradas a la historia de la filosofía. 


\section{Agradecimientos}

Nunca pensé que llegaría el momento fatal. Poco antes hablé con ella por teléfono y la observé con ánimo entusiasta por la publicación de su nuevo libro, por las grabaciones planificadas, por el interés de los alumnos por sus asignaturas de la UNED. Sé que gustaba de Borges y espero que le agrade este artículo. Dedicado a María Teresa Román López, que siempre tuvo palabras amables y sabias. Como Borges, nunca puso fronteras al pensamiento.

Agradezco también a la profesora Purificación Mármol Rodríguez, que me animase a concebir estas reflexiones. Corrigió con delicado esmero el borrador del ensayo y me hizo sugerencias inestimables. 


\section{Bibliografía}

Alazraqui, J. (ed.) (1987). Jorge Luis Borges. El escritor y la critica. Madrid: Taurus.

— (1978). «Jorge Luis Borges». En: J. Roy (comp.), Narrativa y critica de nuestra América. Madrid: Castalia, pp. 34-36.

Almeida, I. (2004). «De Borges a Schopenhauer». Variaciones Borges 17, 103-141.

Almeida, I. \& Parodi, C. (eds.) (2006). El fragmento infinito. Estudios sobre "Tlön, Uqbar, Orbis Tertius» de J. L. Borges. Zaragoza: Prensas Universitarias de Zaragoza.

Balderston, D. (2017). «Cómo escribía Borges: un cuento y un poema». Lo que los archivos cuentan, Vol. 5, pp. 129-152.

Barnatán, M. R. (1978). Conocer Borges y su obra. Barcelona: Dopesa.

Barrenechea, A. M. (1957). La expresión de la irrealidad en la obra de Jorge Luis Borges. México: El Colegio de México.

Benítez, L.; Robles, J.A. (1994). «La vía de las ideas». En: E. de Olaso (ed.), Enciclopedia Iberoamericana de Filosofía, vol. 6. Del Renacimiento a la Ilustración, I. Madrid: Trotta, pp. 111-132.

Berkeley, G. (2013). Comentarios filosóficos; Ensayo de una nueva teoría de la visión; Tratado sobre los principios del conocimiento humano; Tres diálogos entre Hilas y Filonús; Alcifrón. Madrid: Gredos.

Borges, J.L. (2005a). Obras Completas I. Barcelona: RBA.

(2005b). Obras Completas II. Barcelona: RBA.

(2001). Textos recobrados 1931-1955. Barcelona: Emecé Editores.

(2010). Cartas del fervor. Correspondencia con Maurice Abramowicz y Jacobo Sureda (1919-1928). Barcelona: Galaxia Gutenberg.

(2017). Borges Esencial. Barcelona: Real Academia Española. Penguin Random House.

- (1983). Veinticinco agosto 1983 y otros cuentos. Madrid: Siruela.

Borges, J. L., Ferrari, O. (2005). En Diálogo II. México: Siglo XXI.

Borges, J. L., Jurado, A. (2000). Qué es el budismo. Madrid: Alianza Editorial.

Bossong, G. (I988). «La infinitud del lenguaje en la obra de Jorge Luis Borges». En: Victorino Polo (coord.). Oro en la piedra. Homenaje a Borges. Murcia: Editora Regional, pp. 33-53. 
Botero Camacho, M.J. (2006). «Objeción literaria al empirismo de David Hume». Estudios ingleses de la Universidad Complutense, vol. 14, pp. 123-150.

Camurati, M. (20 I I). «Borges ¿̨un argentino extraviado en la metafísica?». Variaciones Borges, 31, pp. 221-231.

Cano López, A. J. (2009). La teoría de las pasiones en David Hume (Del modelo clásico de las pasiones al paradigma ilustrado). Murcia: Universidad de Murcia.

Castany Prado, B. (2012). Que nada se sabe: el escepticismo en la obra de Jorge Luis Borges. Alicante: Universidad de Alicante.

De Toro, A.; De Toro, F. (eds.). (1999). Jorge Luis Borges. Pensamiento y saber en el siglo $X X$. Madrid/Fráncfort del Meno: Iberoamericana-Vervuert.

Kemp Smith, N. (2005, First published 1941). The Philosophy of David Hume. Basingstoke, England: Palgrave.

Hume, D. (1981). Tratado de la naturaleza humana. Madrid: Editora Nacional.

(2004). Investigación sobre el entendimiento humano. Madrid: Istmo.

(2005). Diálogos sobre la religión natural. Madrid: Tecnos.

Johnson, D. E. (2012). Kant's Dog. On Borges, Philosophy, and the Time of Translation. New York: Suny Press.

Lema-HincapiÉ, A. (2002). «Borges y la Filosofía Occidental: algunos momentos de la Crítica». Praxis Filosófica, no 14, pp. 99-114.

Martín, M. (2002). «Borges, perplejo defensor del idealismo». Variaciones Borges. 13, pp. 7-21.

- (2006). «Tras el rumbo de Hume en la invención de Tlön. Versiones paródicas de El Otro, El Mismo». En: I. Almeida \& C. Parodi (eds.), El fragmento infinito. Estudios sobre "Tlön, Uqbar, Orbis Tertius" de J. L. Borges. Zaragoza: Prensas Universitarias de Zaragoza, pp. 123-136.

Mateos, Z. (1998). La filosofía en la obra de Jorge Luis Borges. Buenos Aires: Biblos.

Molloy, S. (1979). Las letras de Borges. Buenos Aires: Editorial Sudamericana.

Moulines, C.U. (1999). «El idealismo más consecuente según Borges: la negación del tiempo». En: A. de Toro, F. de Toro (eds.), Jorge Luis Borges. Pensamiento y saber en el siglo XX. Madrid/Fráncfort en Meno: Iberoamericana-Vervuert, pp. 179-187.

Moure, C. (2013). «Borges y la refutación (poética) del tiempo». Variaciones Borges, 35 , pp. 245-264.

Nuño, J. (1986). La filosofía de Borges. Mexico: Fondo de Cultura Económica.

O'Connor, D. (2001). Hume on Religion. London: Routledge. 
ReID, TH. (2004). Investigación sobre la mente humana según los principios del sentido común. Madrid: Trotta.

Rodero, J. (2006). La edad de la incertidumbre. Un estudio del cuento fantástico del siglo XXI en Latinoamérica. New York: Peter Lang.

Román López, M.T. (20I0). «UNA APROXIMACIÓN A LAS FILOSOFÍAS ORIENTALES NO DUALES». Éndoxa, Series Filosóficas, 25, pp. 103-127.

Savater, F. (2008). Borges: La ironía metafísica. Barcelona: Ariel.

VÁzquez. M.E. (1984). Borges, sus días y su tiempo. Buenos Aires: Javier Vergara.

VAsquez, M.M. (2011). «Metarrelatos, espejos y mundos posibles en Tlön, Uqbar, Orbis Tertius de Borges». Acta literaria, no 42, I Sem. 9-31.

Velarde Lombaña, J. (2001). "Razón ilustrada y agnosticismo». Daimon. Revista Internacional de Filosofía, Suplemento 4, pp. 287-296.

Vitiello, V. (2007). Borges: memoria y lenguaje. Madrid: Círculo de Bellas Artes.

VV.AA. (2016). A través del espejo (Antología a cargo de Jesús Ibañez). Girona: Atalanta.

Enviado: 3/07/2018

Aceptado: 22/10/2018

Este trabajo se encuentra bajo una licencia de Creative Commons ReconocimientoNoComercial-SinObraDerivada 4.0 
